\title{
Aftershock observation of the 2011 off the Pacific coast of Tohoku Earthquake by using ocean bottom seismometer network
}

\author{
Masanao Shinohara ${ }^{1}$, Tomoaki Yamada ${ }^{1}, K_{\text {Kazuo Nakahigashi }}{ }^{1}$, Shin'ichi Sakai ${ }^{1}$, Kimihiro Mochizuki ${ }^{1}$, Kenji Uehira ${ }^{2}$, \\ Yoshihiro Ito $^{3}$, Ryusuke Azuma ${ }^{4}$, Yuka Kaiho ${ }^{5}$, Tetsuo No ${ }^{5}$, Hajime Shiobara ${ }^{1}$, Ryota Hino ${ }^{3}$, Yoshio Murai ${ }^{4}$, \\ Hiroshi Yakiwara ${ }^{6}$, Toshinori Sato ${ }^{7}$, Yuya Machida ${ }^{1}$, Takashi Shinbo ${ }^{1}$, Takehi Isse ${ }^{1}$, Hiroki Miyamachi ${ }^{6}$, \\ Koichiro Obana $^{5}$, Narumi Takahashi ${ }^{5}$, Shuichi Kodaira ${ }^{5}$, Yoshiyuki Kaneda ${ }^{5}$, Kenji Hirata ${ }^{8}$ \\ Sumio Yoshikawa ${ }^{8}$, Kazushige Obara ${ }^{1}$, Takaya Iwasaki ${ }^{1}$, and Naoshi Hirata ${ }^{1}$ \\ ${ }^{1}$ Earthquake Research Institute, University of Tokyo, Tokyo 113-0032, Japan \\ ${ }^{2}$ Institute of Seismology and Volcanology, Kyushu University, Shimabara 855-0843, Japan \\ ${ }^{3}$ Graduate School of Science, Tohoku University, Sendai 980-8578, Japan \\ ${ }^{4}$ Institute of Seismology and Volcanology, Hokkaido University, Sapporo 060-0810, Japan \\ ${ }^{5}$ Japan Agency for Marine-Earth Science and Technology, Yokosuka 237-0061, Japan \\ ${ }^{6}$ Faculty of Science, Kagoshima University, Kagoshima 892-0871, Japan \\ ${ }^{7}$ Graduate School of Science, Chiba University, Chiba 263-8522, Japan \\ ${ }^{8}$ Meteorological Research Institute, Japan Meteorological Agency, Tsukuba 305-0052, Japan
}

(Received April 14, 2011; Revised May 13, 2011; Accepted May 19, 2011; Online published September 27, 2011)

The 2011 off the Pacific coast of Tohoku Earthquake occurred offshore of northeast Japan region on March 11th, 2011. In order to study the aftershock activity of this event, we started deployment of seventy-two ocean bottom seismometers (OBSs) four days after the mainshock. In the south of the source region, thirty-four longterm OBSs (LT-OBSs) had been deployed before the occurrence of the mainshock, and we recovered three LTOBSs to clarify the depth distribution of aftershocks. Using the data of OBSs, ninety-nine aftershocks were located. Most of the aftershocks were located in a depth range of 5-30 km and concentrate in the plate boundary region. In addition, aftershocks occurred within the subducting oceanic crust and the $6.2-\mathrm{km} / \mathrm{s}$ layer of the landward plate. No aftershocks were found in the mantle of the subducting plate. From the results of a previous seismic survey using OBSs and controlled sources, the subducting Philippine Sea plate is estimated to be in contact with the subducting Pacific plate. The southern end of the seismic activity region of the aftershocks corresponds to the contact region of two subducting plates. We infer that the rupture of the mainshock sequence was terminated at the oceanic plate contact region.

Key words: The 2011 off the Pacific coast of Tohoku Earthquake, aftershock, subduction, ocean bottom seismometer (OBS).

\section{Introduction}

The 2011 off the Pacific coast of Tohoku Earthquake $\left(M_{\mathrm{JMA}}=9.0\right)$ occurred offshore of the northeast region of Japan on March 11th, 2011. The source region of this earthquake is considered to spread over a large region with a width of $500 \mathrm{~km}$. Many aftershocks occurred following the mainshock, the largest of magnitude $M=7.7$ thirty minutes after the mainshock in the southern area of the source region. In the source region of the mainshock, several large earthquakes with a magnitude greater than 7 occurred and the source regions of these earthquakes were obtained (Yamanaka and Kikuchi, 2004). However, the magnitude of the 2011 Tohoku Earthquake was larger than those of previous large earthquakes and the source region of the mainshock includes those of previous earthquakes. Judging from its source mechanism, the 2011 Tohoku Earthquake occurred at the plate boundary between the subducting $\mathrm{Pa}-$

Copyright (c) The Society of Geomagnetism and Earth, Planetary and Space Sciences (SGEPSS); The Seismological Society of Japan; The Volcanological Society of Japan; The Geodetic Society of Japan; The Japanese Society for Planetary Sciences; TERRAPUB.

doi:10.5047/eps.2011.05.020 cific plate and the landward plate. Knowledge of precise aftershock distribution is inevitably important to understand the generation mechanism of this large earthquake. In addition, this kind of information provides useful constraints for studies of rupture in such a wide source region. The precise determination of aftershock distribution, however, is difficult using only land seismic network data when the source region is widely spread under an offshore area near a coast line. It is widely known that an ocean bottom seismometer (OBS) observation is essential to obtain a high-resolution aftershock distribution associated with large earthquakes that occur in the marine environment (e.g., Shinohara et al., 2004, 2008; Sakai et al., 2005; Hino et al., 2006).

From the time intervals of large earthquakes, the Headquarters for Earthquake Research Promotion evaluated long-term possibility earthquake occurrence in the regions along the Japan trench. The probability of an earthquake with a magnitude of 7.5 occurrence in the next thirty years is estimated to be $99 \%$ off the Miyagi region. Based on this high probability, twenty OBSs were being operated in the region off Miyagi at the occurrence of the 2011 Tohoku Earthquake. On the other hand, repeating large character- 
istic earthquakes with a magnitude of 7 and a recurrence interval of twenty years have occurred in the off-Ibaraki region (Mochizuki et al., 2008). To investigate a mechanism of the repeating earthquakes, thirty-four long-term OBS were installed in the off-Ibaraki region, by which the 2011 Tohoku Earthquake was also observed. These data from the deployed OBSs will contribute to the improvement of the hypocenter location in the source region. However, the region where the OBS networks were deployed was limited compared with the source region of the 2011 Tohoku Earthquake. To reveal precise aftershock distribution, an OBS network covering the whole source region is needed.

Four days after the mainshock, we started an aftershock observation using pop-up type OBSs in order to obtain the detailed aftershock activity of the 2011 Tohoku Earthquake. We deployed a total of seventy-two OBSs in the source region of the mainshock until the beginning of April, 2011. During the deployment of OBSs, six OBSs which were installed before the earthquake were recovered in order to obtain a detailed aftershock distribution, especially depth distribution in the mainshock source region. Three of the recovered OBSs were positioned in the southernmost source region. This paper focuses on the description of the OBS observation and the precise aftershock distribution in the southernmost source region, with an emphasis on depths of events, using the OBSs that were recovered two weeks after the occurrence of the earthquake together with the land-based seismic station close to the recovered OBSs. In the future, the precise aftershock distribution in the whole observation area will be determined using data from all the OBSs.

\section{Observation}

Four days after the 2011 off the Pacific coast of Tohoku Earthquake, we started to deploy seventy-two OBSs in the source region by $\mathrm{R} / \mathrm{V}$ Kairei (Japan Agency for Marine-Earth Science and Technology, JAMSTEC) and M/V Shinyu-maru (Shin Nippon Kaiji Co., chartered by the Earthquake Research Institute, University of Tokyo) in order to study the aftershock activity of this event. Consequently, we observed the aftershocks at 121 sites including the pre-installed OBS sites in total (Fig. 1). The observation area is $500 \mathrm{~km} \times 200 \mathrm{~km}$ and has high aftershock activity, which is estimated from the land seismic network. The spatial interval of OBSs is approximately $25 \mathrm{~km}$ to cover the whole source region. We used various types of the digital recording OBS system (Fig. 1). In addition, ocean bottom pressure meters (OBPs) were deployed near the epicenter of the mainshock to detect vertical crustal movement.

During the deployment, the R/V Kairei recovered three OBSs which had been deployed before the occurrence of the mainshock. Three OBSs were positioned near the epicenter of the mainshock. However it is difficult to obtain the precise location of aftershocks in the northern source region even if data from the OBSs and the land seismic network were used due to the small number of OBSs and the long distance between the OBS network and the land network. Three long-term OBSs of thirty-four OBS array operated off Ibaraki were successfully recovered at the end of the Kairei cruise. These three long-term OBSs had been de-

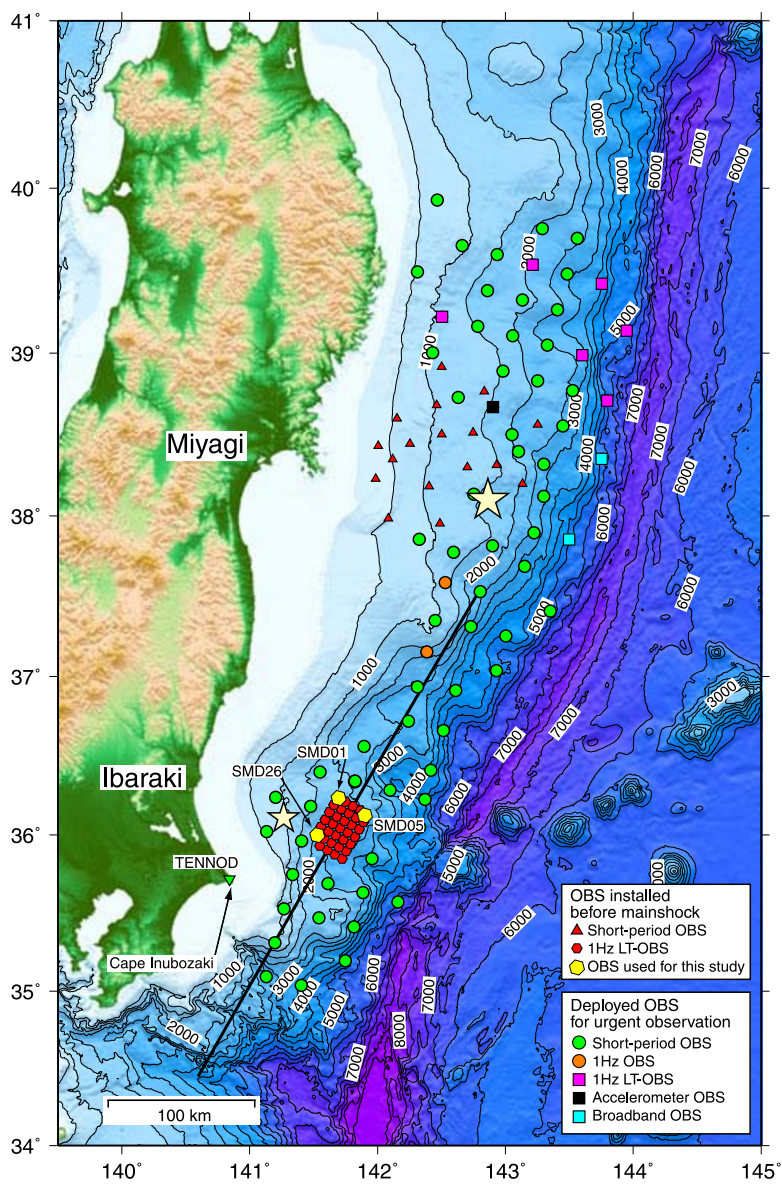

Fig. 1. Location map of ocean bottom seismometers with bathymetric features as of April 8th, 2011. Triangle and hexagons indicate the positions of pop-up type OBSs deployed before the mainshock. Circles and squares denote the positions of OBSs deployed for an urgent observation after the mainshock. Various types of OBSs are used for the aftershock observation. See an inset legend. Yellow hexagons indicate the position of the OBSs which were recovered on March 30th, 2011 and were used for a preliminary analysis. Large and small stars indicate the epicenters of the mainshock and the largest aftershock, respectively. Thick line indicates the profile of the seismic survey using OBSs, an airgun array and explosives in 2008 (Nakahigashi et al., in preparation).

ployed within the source region before the occurrence of the 2011 Tohoku Earthquake and recorded the seismic waves from the mainshock and the largest aftershock. Three OBSs in the southern source region are close to the land seismic stations. Therefore we concentrated on location of aftershocks with high accuracy in the southernmost source region using three long-term OBSs and land stations.

The recovered OBSs from the off-Ibaraki region have three-component velocity sensitive electro-magnetic geophones with a natural frequency of $1 \mathrm{~Hz}$, and use a titanium sphere as a pressure vessel. The longest recording period reaches one year for this type of OBS (Kanazawa et al., 2009). The resolution of the A/D conversion is twenty-four bits. Accurate timing, estimated to be within $0.05 \mathrm{~s}$, is provided by a precise crystal oscillator. All the OBSs are of a pop-up type with an acoustic release system. The OBS position at the sea floor was estimated by using acoustic ranging and ship GPS positions. The accuracy of the OBS positions at the sea floor is estimated to be a few tens of meters. We also determined the water depth of the OBSs by 


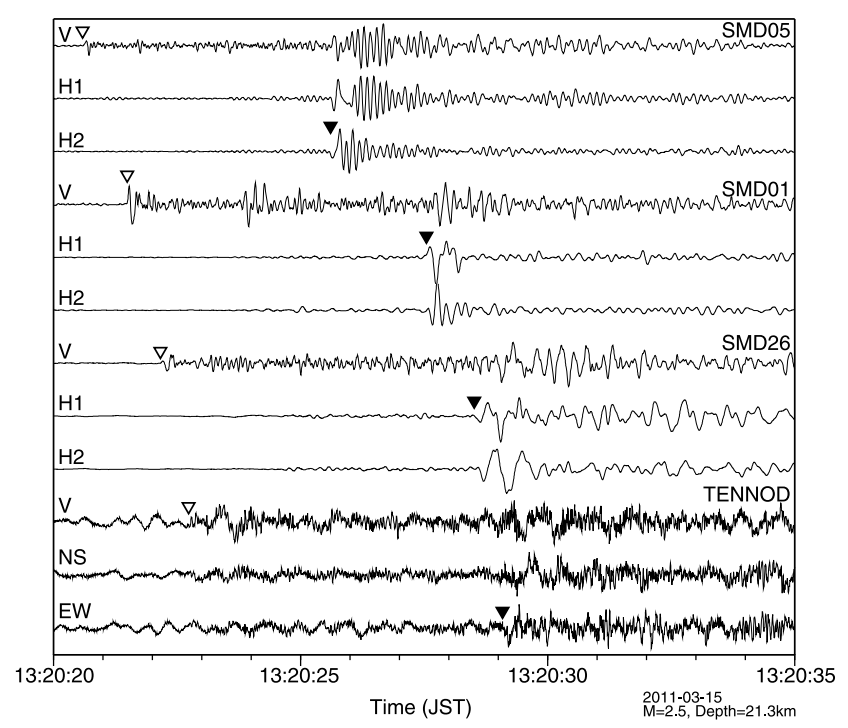

Fig. 2. Example of seismograms of an aftershock for three OBSs and one land station. See Fig. 1 for positions of the OBSs and the land station. Three components are shown and no filter is applied. The origin time of the event is 01:30:15.9 JST on March 15th 2011 and the estimated coordinate of the hypocenter is $36^{\circ} 05.1^{\prime} \mathrm{N}, 141^{\circ} 47.7^{\prime} \mathrm{E}$. The depth and magnitude of the event are $21.3 \mathrm{~km}$ and 2.5 , respectively. Each trace is normalized by its maximum amplitude. The OBS number is labeled above each trace. $V$ and $H$ denote vertical component and horizontal components of the seismogram, respectively. Solid and open inverted triangles indicate $P$ - and $S$-wave arrivals, respectively.

the acoustic ranging.

\section{Data and Hypocenter Determination}

We used waveform data from the OBSs recovered off Ibaraki and three land seismic stations. The retrieved OBSs have a recording period of approximately two weeks after the occurrence of the mainshock and were positioned in the southern area of the source region. We selected 113 events whose epicenter is close to the recovered OBSs from the hypocenter catalog which the Japan Meteorological Agency (JMA) had determined using the data of the permanent telemetered land seismic network operated by the National Research Institute for Earth Science and Disaster Prevention (NIED), JMA, and universities (the JMA unified hypocenter catalog). The selected events occurring from March 12th to 19th were used for a preliminary analysis. Data from all OBSs and land stations were combined into multistation waveform data files for each event, for which $P$ - and $S$-wave arrival times were picked on a computer display (Urabe and Tsukada, 1991). Although large earthquakes continuously occurred in the period of the analysis, $P$ - and $S$-wave arrivals can be picked with small errors (Fig. 2).

Precise velocity structure in the study region is essential for accurate hypocenter location. In 2008, extensive seismic experiments were carried out in the study area using controlled seismic sources and OBSs to obtain a detailed seismic structure (Nakahigashi et al., in preparation). The seismic survey used thirty-nine OBSs and controlled sources of 100-liter airgun array and 60-kg explosives. Explosives were positioned approximately every $3 \mathrm{~km}$ on the profile and the OBSs recorded deep penetrated seismic waves.

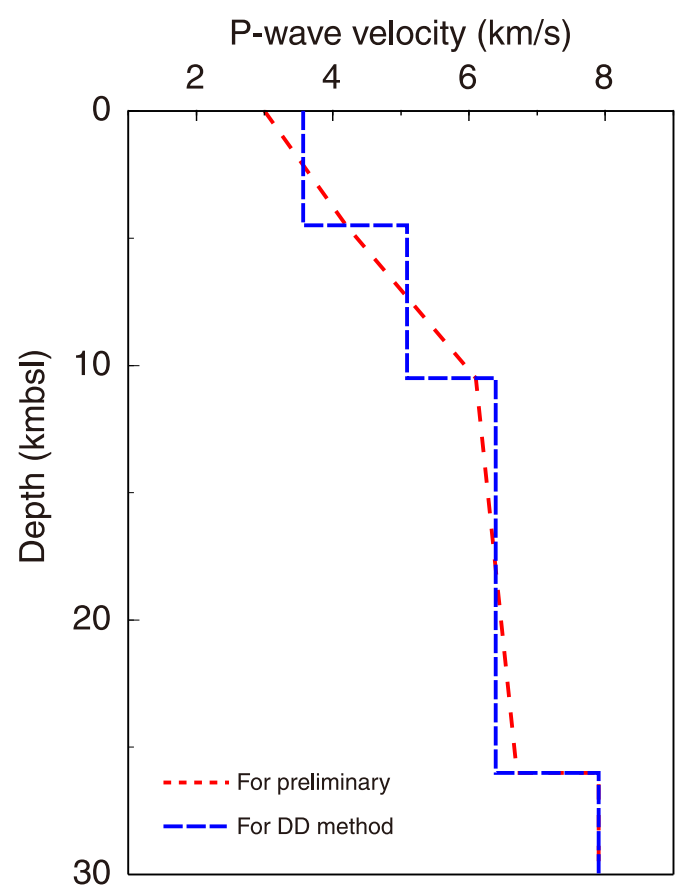

Fig. 3. $\quad P$-wave velocity structure models for the hypocenter determination. The red dotted line and blue dotted line denote the $P$-wave velocity models for the preliminary location and the double-difference method, respectively. The model is derived from the refraction experiment carried out using the OBSs, an airgun array and explosives in 2008 (Nakahigashi et al., in preparation).

First one-dimensional (1-D) $P$-wave velocity structure in a shallow region just below each OBS was obtained by $\tau-p$ method (Shinohara et al., 1994) using airgun records. The set of 1-D $P$-wave velocity structure just below each OBS was used to construct an initial model for the 2-D ray tracing method (Zelt and Smith, 1992). This used a trial-anderror method to obtain a 2-D velocity model that can explain the observed travel times of first and later arrivals for all the OBSs on the profiles.

Although the study area has large lateral heterogeneity in the seismic structure caused by the plate subduction, a simple one-dimensional velocity structure for the hypocenter location was modeled by introducing the results of refraction study due to the relatively small area of this study (Fig. 3). We used the seismic deep structure just below the OBS array from the result of the 2008 seismic survey for the hypocenter location. The first layer (sedimentary layer) has $P$-wave velocities from $3.0 \mathrm{~km} / \mathrm{s}$ to $4.2 \mathrm{~km} / \mathrm{s}$, and $P$-wave velocities in the second layer are $4.2-6.1 \mathrm{~km} / \mathrm{s}$. The thicknesses of the first layer and the second layer are $4.5 \mathrm{~km}$ and $6 \mathrm{~km}$, respectively. The third layer has the $P$-wave velocity of $6.1 \mathrm{~km} / \mathrm{s}$ to $6.7 \mathrm{~km} / \mathrm{s}$ and thickness of $15.5 \mathrm{~km}$. An interface between the landward plate and the subducting Pacific plate is clearly imaged by the reflected waves; however, the velocity difference of the two plates is small. A fourth layer corresponding to the mantle of the Pacific plate has $P$-wave velocity $\left(P_{\mathrm{n}}\right.$ velocity) of $7.9 \mathrm{~km} / \mathrm{s}$. We also assumed that the ratio of $P$-wave to $S$-wave velocity in the crust and mantle is 1.73 , because $S$-wave structure is not available. Since the velocities of sedimentary layers are known to have a $P$-wave velocity smaller than $3 \mathrm{~km} / \mathrm{s}$ from the result of the 
seismic survey and $S$-wave velocity is thought to be small in the sediment, the estimated travel times of $P$ - and $S$-waves calculated by the location program for OBSs must be corrected. The $V_{p} / V_{s}$ ratio of 3 is assumed to calculate $S$-wave correction value for the sedimentary layer.

Hypocenters were determined by the maximumlikelihood estimation technique of Hirata and Matsu'ura (1987). Due to uncertainty of the thickness of the sedimentary layer and seismic velocity in the sedimentary layer, we used the following method. First, we located the hypocenter using $P$ - and $S$-wave arrival times with correction values for the sedimentary layer calculated by using the results of the 2008 seismic survey. Averaged differences between observed travel time and estimated travel times (O-C times) for each OBS were calculated. The averaged $\mathrm{O}-\mathrm{C}$ times are added to the previous correction values, and the hypocenters were relocated. We repeated this procedure two times. After this procedure, the averaged $\mathrm{O}-\mathrm{C}$ times become less than $0.1 \mathrm{~s}$ for both the $P$-wave and $S$-wave. Finally, hypocenters were relocated by the double-difference (DD) method (Waldhauser and Ellsworth, 2000). We reconstructed a velocity structure for the DD method (Fig. 3) because the DD method accepts a 1-D structure where each layer has a constant velocity. A velocity of each layer for the DD method was determined based on the velocity structure for the preliminary location. Magnitudes of the aftershocks were estimated using the maximum amplitudes of the data recorded by the land array (Watanabe, 1971).

\section{Results and Discussion}

The OBS and land station network located ninety-nine earthquakes using the DD method (Fig. 4). During the preliminary location, errors of each aftershock location were calculated from the total covarience matrix of the location program (Hirata and Matsu'ura, 1987). As a result, the aftershocks have small errors, thereby confirming the potential to precisely locate aftershocks. Average location errors are $1.2 \mathrm{~km}$ in the horizontal direction and $1.3 \mathrm{~km}$ in depth. Magnitudes of the ninety-nine aftershocks ranged from 2.2 to 6.0 .

Although the study area is a small portion of the whole source region, the epicenter distribution is not uniform. In the epicenter distribution, the aftershocks may be divided into a number of clusters from a geometrical view point. Most of the aftershocks are located in a depth range of 5$30 \mathrm{~km}$ in the study area. The aftershocks clearly form a plane dipping landward in the study area. Aftershocks beneath the slope on the island arc side are frequent, but there is relatively low seismic activity beneath the area within the trench where the water depth is greater than about $3000 \mathrm{~m}$. No hypocenters were detected below a depth of $30 \mathrm{~km}$.

Among ninety-nine hypocenters, eighty-eight hypocenters correspond to those determined from the data of the land seismic network by the JMA. We compare our results to those by the JMA (Fig. 5). Although most hypocenters by the JMA in our studied area, which were determined only using the data from the land network, are scattered in a large depth range to $80 \mathrm{~km}$, all hypocenters determined by the OBS network have focal depths of less than $30 \mathrm{~km}$. This

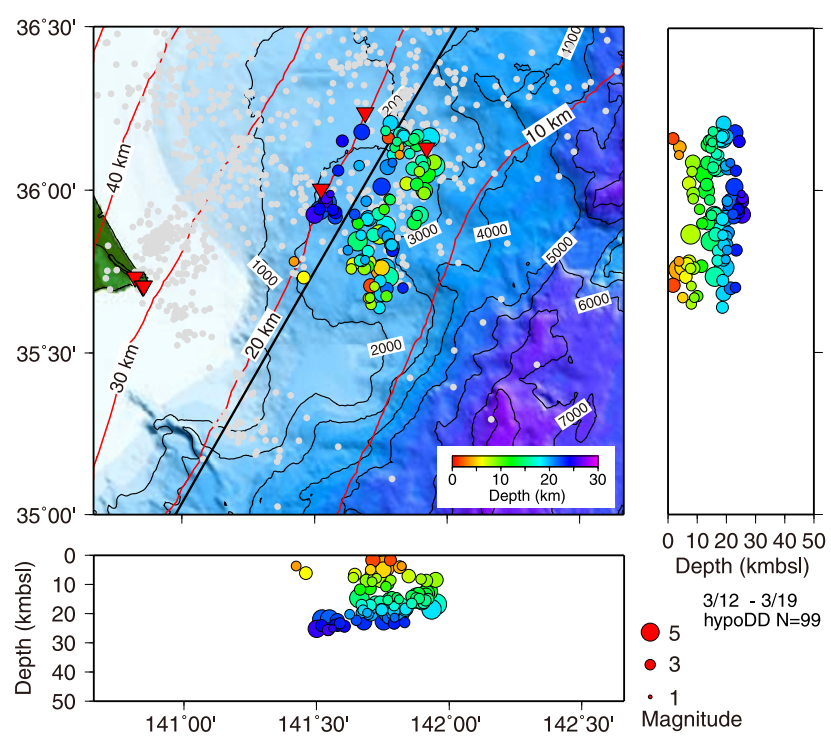

Fig. 4. Final hypocenter distribution (March 12th-March 19th, 2011) derived by using the double-difference method with bathymetry. The inverted red triangles indicate the positions of the pop-up type OBSs and the land seismic station used for this study. The circles filled with color represent hypocenters. The depth of events is color-coded. The diameters of the circles are proportional to the magnitudes. Grey circles indicate epicenters of aftershocks determined by the JMA for the same period. Thick line indicates the profile of the seismic survey. Red contours indicate depths of surface of the subducting Pacific plate by a model estimated hypocenter distribution and seismic structures using OBSs. No exaggeration for vertical direction is applied. In the vertical section, the concentration of the aftershocks in depths of 5-30 km is clearly recognized. From the W-E vertical cross section, the aftershocks become deeper westward.

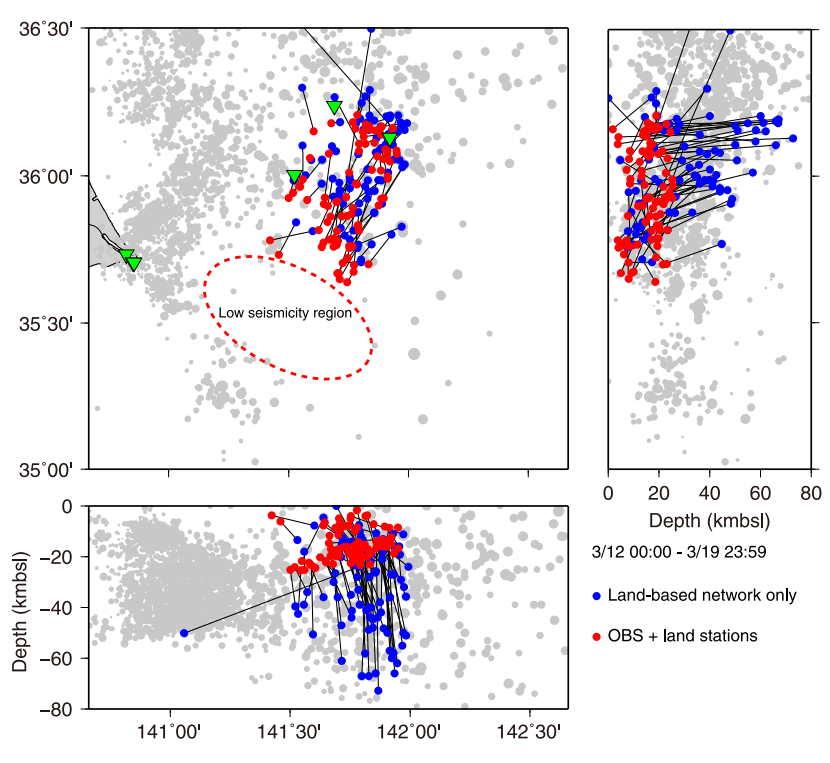

Fig. 5. Comparison between hypocenters by the OBS networks (red circles) and those determined by the JMA (blue circles). The inverted green triangles indicate positions of the pop-up type OBSs and the land-based seismic station. Grey circles indicate hypocenters of aftershocks determined by the JMA from March 12th to 19th. Note that a low seismicity area is seen $50 \mathrm{~km}$ south of the OBS network.

indicates that OBS observation is useful for determination of the depth of each event with higher accuracy. Because all hypocenters by the OBS network were determined shallower than those by JMA, the depth of the rupture region 


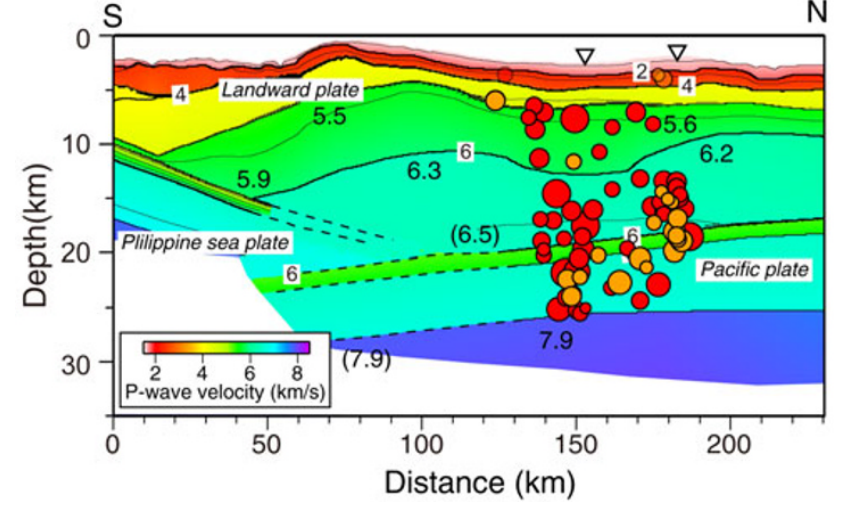

Fig. 6. Vertical section of $P$-wave velocity structure and the aftershock distribution along the refraction profile (Nakahigashi et al., in preparation). The aftershocks within a $15-\mathrm{km}$-wide box on both sides along the profile are projected onto the seismic survey profile. The aftershocks indicated by orange circles have a distance less than $5 \mathrm{~km}$ from the profile. Contours and numerals indicate $P$-wave velocities. Contour interval is $0.4 \mathrm{~km} / \mathrm{s}$. The profile of the refraction survey (black line in Fig. 4) is parallel to the strike of the trench. Note a large exaggeration for the vertical axis. Red circles indicate the hypocenters of the aftershocks, and diameters of circles correspond to magnitudes. Inverted triangles indicated the projected position of the pop-up type OBSs. Most of the aftershocks occurred in the plate boundary region. There is no seismicity in the contact region of two oceanic plates.

which is considered to correspond to the plate boundary is inferred to be around $20 \mathrm{~km}$ from our results.

In a cross section of the hypocentral distribution projected on a vertical plane along the seismic survey (Nakahigashi et al., in preparation), we can clearly see the relation between the aftershock distribution and the seismic velocity structure (Fig. 6). Though we could locate only ninety-nine aftershocks in the southernmost part of the source region during the limited observation period, the aftershocks mainly occurred around the plate boundary between the landward plate and the subducting Pacific plate. In addition hypocenters of the aftershocks are spread in the subducting oceanic crust and the $5.5-\mathrm{km} / \mathrm{s}$ layer in the landward plate. The aftershocks seem to be concentrated within the subducting oceanic crust and the $6.2-\mathrm{km} / \mathrm{s}$ layer in the overriding plate. We found no aftershock in the mantle of the subducting Pacific plate.

The rupture of the mainshock is estimated to propagate from the hypocenter which is positioned off Miyagi to the south (Honda et al., 2011). Since the aftershocks determined by the OBS network concentrate around the plate boundary between the landward plate and the subducting Pacific plate, the rupture of the mainshock sequence is thought to propagate to the study area. Our OBS network is located at the southernmost region of the source region. There is a clear difference in a view of an aftershock activity. A low seismicity area lies $50 \mathrm{~km}$ south of the OBS network in this study. This difference of the seismicity is also seen from an epicenter distribution determined the JMA (Fig. 5). Therefore we interpret that the rupture was terminated to the boundary of the seismicity. In the velocity structure model obtained by the seismic survey it is clearly imaged that the Philippine plate is subducting below the landward plate. The Philippine Sea plate is positioned above the subducting Pacific plate and is estimated to come into contact with the Pacific plate at the depth of $20 \mathrm{~km}$ off Cape-Inubozaki. The boundary between the high and low seismicity region corresponds to the position of the contact between the Philippine plate and the Pacific plate. Consequently we infer that the propagation of the rupture during the mainshock sequence was terminated at the contact point with two subducting oceanic plates. The subducting Philippine Sea plate may play an important role such as acting as a barrier in the propagation of the rupture during the mainshock sequence.

\section{Conclusions}

To obtain detailed aftershock distribution of the 2011 off the Pacific coast of Tohoku Earthquake, seventy-two OBSs were deployed from March 15th to April 1st, 2011 in the whole source region of the mainshock. Because fifty-two OBSs had been installed in a portion of the source region and were observing earthquakes, we observed aftershocks using more than 120 OBSs as of April 8th, 2011. Six OBSs among the installed OBSs were recovered during the deployment cruise. The data from three OBSs deployed in the southernmost area of the source region were used for urgent analysis to determine depths of aftershocks. We obtained locations of the ninety-nine aftershocks with high spatial resolution from March 12th to 19th, 2011. Most of the aftershocks are located in a depth range of $5-30 \mathrm{~km}$. There is little seismic activity beneath the area within the trench where the water depth is greater than about $3000 \mathrm{~m}$. In a vertical cross section of the hypocentral distribution, the aftershocks occurred in the plate boundary region between the subducting Pacific plate and the landward plate including the subducting oceanic crust and the $6.2-\mathrm{km} / \mathrm{s}$ layer in the overriding plate. A low seismicity area lies $50 \mathrm{~km}$ south of the OBS network in this study. This difference of the seismicity is also seen from an epicenter distribution determined by the JMA. The boundary of seismic activity corresponds to the position of the contact between the subducting Philippine plate and the subducting Pacific plate. We infer that the propagation of the rupture during the mainshock sequence was terminated at the contact point with two subducting oceanic plates.

Acknowledgments. We express thanks to Messrs. S. Hashimoto, T. Yagi, and H. Abe for helps in preparation of the OBS observation. The work of the officers and crew of R/V Kairei and M/V Shinyu-maru is appreciated. We also thank Ms. Y. Nihei for the OBS data processing. Dr. T. Kanazawa gave us useful advice about carrying out this study. This study is partly supported by the Special Coordination Funds for the Promotion of Science and Technology (MEXT, Japan) titled as the integrated research for the 2011 off the Pacific coast of Tohoku Earthquake. Most of the figures were created using GMT (Wessel and Smith, 1991).

\section{References}

Kanazawa, T., M. Shinohara, and H. Shiobara, Recent progress in seafloor earthquake observations and instruments in Japan, Zisin 2, 61, S55-S68, 2009 (in Japanese with English abstract).

Hirata, N. and M. Matsu'ura, Maximum-likelihood estimation of hypocenter with origin time eliminated using nonlinear inversion technique, Phys. Earth Planet. Inter., 47, 50-61, 1987.

Hino, R., Y. Yamamoto, A. Kuwano, M. Nishino, T. Kanazawa, T. Yamada, K. Nakahigashi, K. Mochizuki, M. Shinohara, K. Minato, G. Aoki, 
N. Okawara, M. Tanaka, M. Abe, E. Araki, S. Kodaira, G. Fujie, and Y. Kaneda, Hypocenter distribution of the main- and aftershocks of the 2005 Off Miyagi Prefecture Earthquake located by ocean bottom seismographic data, Earth Planets Space, 58, 1543-1548, 2006.

Honda, R., Y. Yukutake, H. Ito, M. Harada, T. Aketagawa, A. Yoshida, S. Sakai, S. Nakagawa, N. Hirata, K. Obara, and H. Kimura, A complex rupture image of the 2011 off the Pacific coast of Tohoku Earthquake revealed by the MeSO-net, Earth Planets Space, 63, this issue, 583588,2011

Mochizuki, K., T. Yamada, M. Shinohara, Y. Yamanaka, and T. Kanazawa, Weak interplate coupling by seamounts and repeating $\mathrm{M} \sim 7$ earthquakes, Science, 321, 5839, 1194-1197, doi:10.1126/science.1160250, 2008.

Sakai, S., T. Yamada, M. Shinohara, H. Hagiwara, T. Kanazawa, K. Obana, S. Kodaira, and Y. Kaneda, Urgent aftershock observation of the 2004 off the Kii Peninsula Earthquake using ocean bottom seismometers, Earth Planets Space, 57, 363-368, 2005.

Shinohara, M., N. Hirata, and N. Takahashi, High resolution velocity analysis of ocean bottom seismometer data by the $\tau$-p method, Mar. Geophys. Res., 16, 185-199, 1994.

Shinohara, M., T. Yamada, T. Kanazawa, N. Hirata, Y. Kaneda, T. Takanami, H. Mikada, K. Suyehiro, S. Sakai, T. Watanabe, K. Uehira, Y. Murai, N. Takahashi, M. Nishino, K. Mochizuki, T. Sato, E. Araki, R. Hino, K. Uhira, H. Shiobara, and H. Shimizu, Aftershock observation of the 2003 Tokachi-oki Earthquake by using dense ocean bottom seismometer network, Earth Planets Space, 56, 295-300, 2004.

Shinohara, M., T. Kanazawa, T. Yamada, K. Nakahigashi, S. Sakai, R. Hino, Y. Murai, A. Yamazaki, K. Obana, Y. Ito, K. Iwakiri, R. Miura,
Y. Machida, K. Mochizuki, K. Uehira, M. Tahara, A. Kuwano, S. Amamiya, S. Kodaira, T. Takanami, Y. Kaneda, and T. Iwasaki, Precise aftershock distribution of the 2007 Chuetsu-oki Earthquake obtained by using an ocean bottom seismometer network, Earth Planets Space, 60, 1121-1126, 2008.

Urabe, T. and S. Tsukada, A workstation-assisted processing system for waveform data from microearthquake networks, Abstracts of Spring Meeting of Seismological Society of Japan, p 70, 1991 (in Japanese).

Waldhauser, F. and W. L. Ellsworth, A double-difference earthquake location algorithm: Method and application to the northern Hayward fault, Bull. Seismol. Soc. Am., 90, 1353-1368, 2000.

Watanabe, H., Determination of earthquake magnitude at regional distance in and near Japan, Zisin 2, 24, 189-200, 1971.

Wessel, P. and W. H. F. Smith, Free software helps map and display data, Eos Trans. AGU, 72, 441, 1991.

Yamanaka, Y. and M. Kikuchi, Asperity map along the subduction zone in northeastern Japan inferred from regional seismic data, J. Geophys. Res., 109, B07307, doi:10.1029/2003JB002683, 2004.

Zelt, C. A. and R. B. Smith, Seismic travel time inversion for 2-D crustal velocity structure, Geophys. J. Int., 108, 16-34, 1992.

M. Shinohara (e-mail: mshino@eri.u-tokyo.ac.jp), T. Yamada, K. Nakahigashi, S. Sakai, K. Mochizuki, K. Uehira, Y. Ito, R. Azuma, Y. Kaiho, T. No, H. Shiobara, R. Hino, Y. Murai, H. Yakiwara, T. Sato, Y. Machida, T. Shinbo, T. Isse, H. Miyamachi, K. Obana, N. Takahashi, S. Kodaira, Y. Kaneda, K. Hirata, S. Yoshikawa, K. Obara, T. Iwasaki, and N. Hirata 